\title{
Analysis of One Bay Residential Building with Combined RCC Frame and Load Bearing Wall Structures
}

\author{
Rajib Maharjan, Vivek Shrestha \\ Lumanti Support Group for Shelter Thapathali, Kathmandu, Nepal \\ Corresponding author:rajib_maharjan@yahoo.com
}

Received: August 13, 2017 Revised: Dec 13, 2017 Accepted: Dec 15, 2017

\begin{abstract}
The major purpose of this study is to justify construction method of a hybrid structure in core area with construction complexity due unsafe excavation conditions and tries to define its rigidity and strength. Both RCC and Frame structure transfer same load to ground through foundation but the transfer mechanism varies. In some practical condition, building construction should be carried out in compact areas with unsafe adjoining building where adequate excavation for foundation cannot be carried out. In such cases, one bay hybrid structure is proposed for construction with combined RCC frame structure and load bearing walls. In these combined cases, both structures works as same unit to transfer building load but the transfer pattern varies. The variable load transfer pattern is due to discontinuity in structural system which also effect on seismic response of the building. The placement of a masonry load bearing structure in RCC frame structure varies design of all structural components of the building. To study actual behavior of hybrid structure in various load condition and introducing cost minimization techniques of buildings structural analysis was carried using ETABS 2016 with composite structural arrangement and with induction of load bearing wall as structural component. By which seismic behavior of building in both cases was obtained as well as reduction in rebar percentage and dimensional reduction of structural components can be achieved.
\end{abstract}

Keywords: Hybrid structure, seismic, load transfer pattern, structural component, cost reduction

\section{Introduction}

A hybrid building consists of two or more lateral load-resisting system which are induced in structure due to conditional requirement or due modification of existing structure [4]. These structures have crucial modeling issues special in the portion in which RCC frame element and load bearing wall structures are connected [5]. The history has shown that hybrid buildings are subjected to high risk and vulnerability during earthquake but the major reason for collapse of these building is due to use of non-engineered methods in construction [10]. Due to use of fragile material and less reliable connection between RCC frame and load bearing wall these building show less performance in lateral load conditions [7]. But in recent condition load bearing wall can be built as monolithic structure to resist shear force in the building which had made hybrid structure efficient in lateral load as well as vertical load condition [9]. The storey displacement, drift, and 
modal time can be significantly decreased when RCC building frame structure is combined with load bearing structure. Also construction advantage such as rapid construction and cost reduction can be obtained [10].

While building a hybrid structure insuring seismic safety is complex task which can be only when technical appropriate combination technique is well studied [1]. For the selection of such techniques existing bearing capacity of structures as well as mechanical property of material should be known and also structural analysis of hybrid structure should be performed to know behavior building in variable load conditions [8]. The insertion masonry structure in RCC can be modeled by using equivalent frame method developed on basis of global seismic responses and damage survey during earthquake. The induced masonry structures are modeled in natural state by using piers, spandrels and rigid joints as to be constructed in natural conditions [3]. For analysis of hybrid structure analysis the use of performance based non-linear analysis is not sufficient since building response is strongly affected by interactive elements showing variable performance based on direction of forces applied in the building [6]. For actual quantitative evaluation of seismic response in terms of strength and ductility an incremental static analysis is essential by which relation between force and displacement and capacity design of the building can be carried on actual based performance [2].

\section{Site Location and Description}

The studied building is located in aboriginal Newari community in Siddhipur Lalitpur district Nepal. Siddhipur has compact core settlement with abundant culturally important monument and is also famous for its enriched Newari cultural.

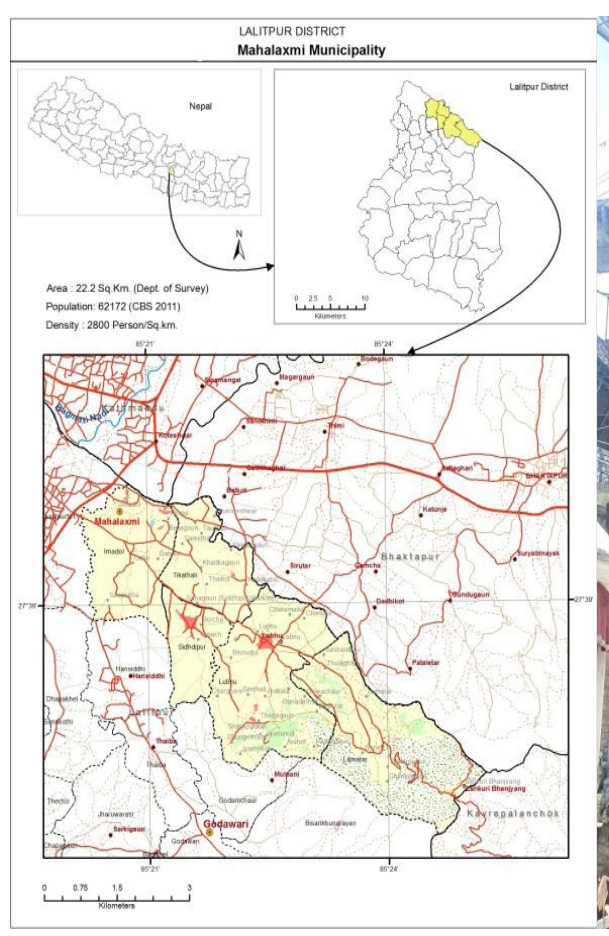

Site Location

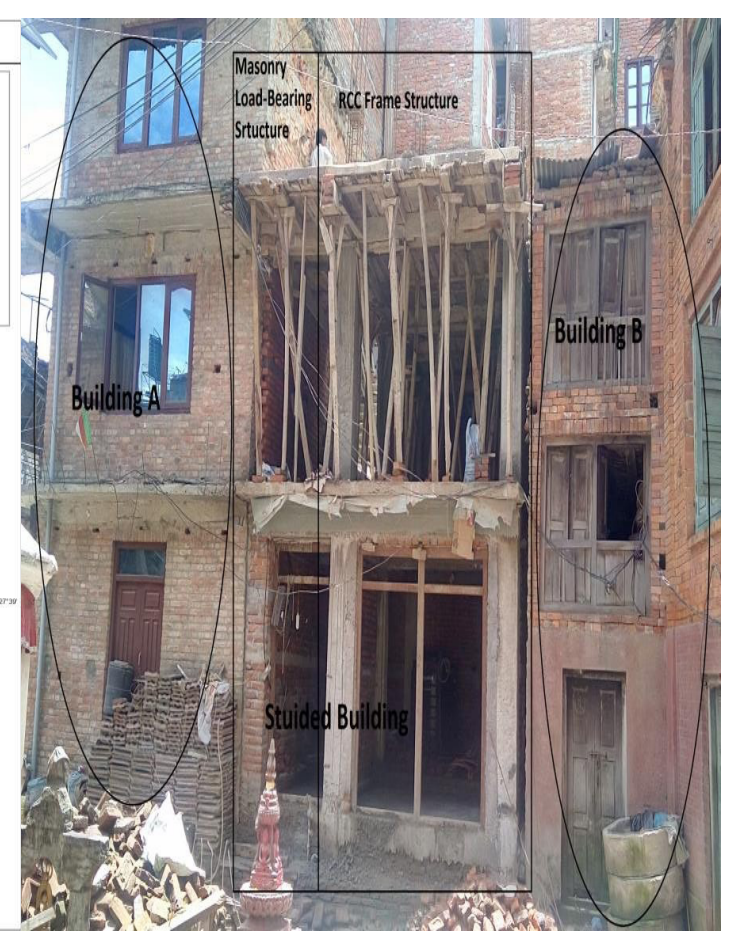

Building Condition

Fig. 1: Site location and description building. 
Fig. 2 represents site location and description of actual studied building. In Fig. 2, studied building is a hybrid building which consists of RCC frame structure and load bearing masonry structure. Similarly, Building A (5+1/2 storey) is load bearing masonry structure with sand- cement mortar and Building B $(3+1 / 2)$ storey load bearing with mud mortar. In this case both Building A and Building B has low depth foundation. While proceeding construction of studied building excavation of foundation was very risky due to both adjoining building but however adequate support can only be used in case of Building B due to its low height and light structure. In case Building B excavation near its foundation was quite impossible since it was a huge structure and supporting building was risky and tough task. So, for safer construction a loading masonry foundation near Building A and RCC footing near Building B was proposed. For proper structure stability and sound engineering construction modeling and design of one bay combined structure was essential.

\section{Material and Methods}

\subsection{Design Aspect}

To analyze the mechanism of building's structural characteristics in hybrid conditions two models were created in Etabs 2016. Model I consist only RCC frame structure with wall load directly to beams and column and Model II consist of RCC building with load bearing masonry structure. The building lies in earthquake zone V and seismic analysis is carried out using IS code 893:2002. The modeling and design of both models are carried out using equivalent static method also known as static method or seismic coefficient method. This is a simple method in which the structure is considered a discrete system and floor loads are divided equally distributed to the floors above and below the storey and also structure flexible and deflect according to location of foundation.

\subsection{Geometric Features and Modeling}
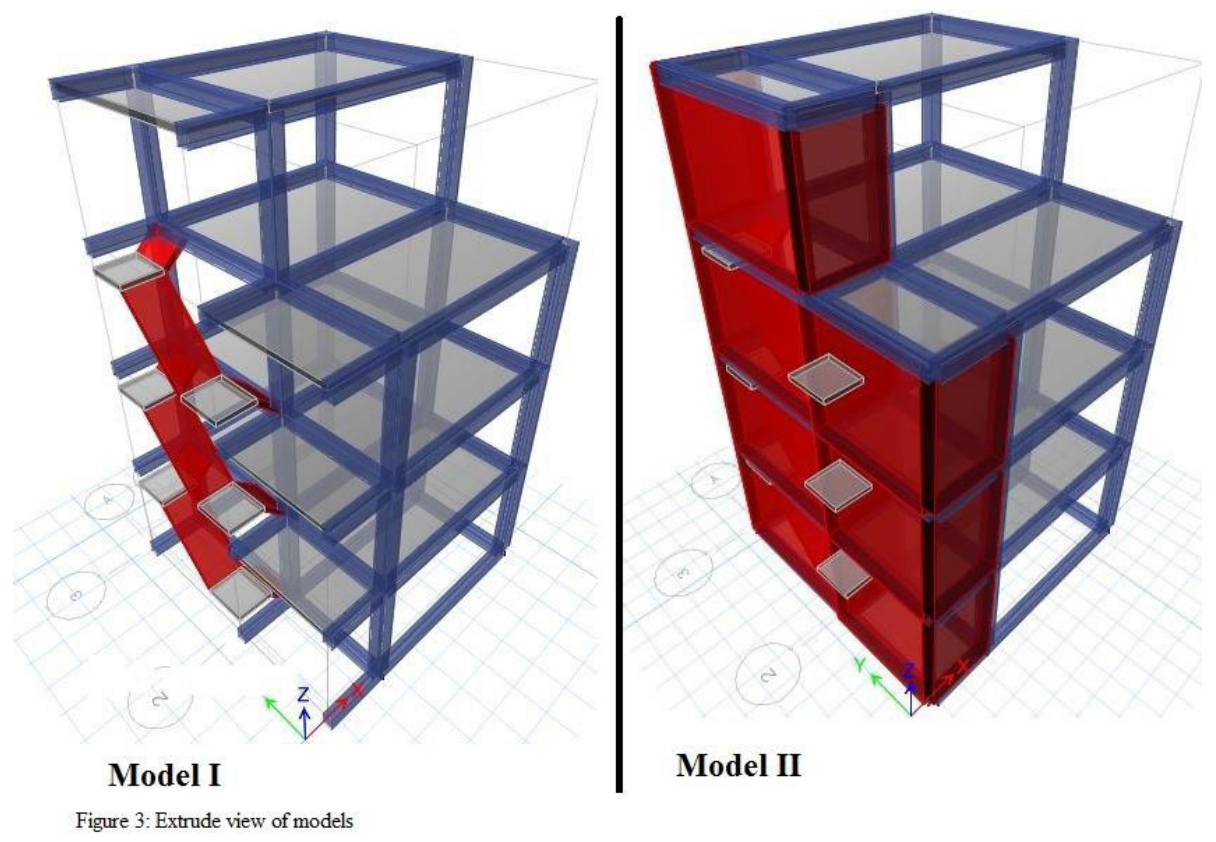

Fig. 2: Extrude view of models

The building is a one bay structure with $31 / 2$ storey each of height $2.74 \mathrm{~m}$, x-dimension $6.7 \mathrm{~m}$ 
and y dimension $6.14 \mathrm{~m}$. The same building is modeled for two variable structural conditions as shown in Fig 3. The size columns, beams, slab thickness and foundation depth are $(300 \times 300) \mathrm{mm}$, $(230 X 300) \mathrm{mm}, 125 \mathrm{~mm}$ and $1.5 \mathrm{~m}$ respectively. In Model II same building features are used but masonry load bearing wall is added. The thickness of wall is $400 \mathrm{~mm}$ in ground floor and $230 \mathrm{~mm}$ in all other respective floors. In this analysis Model I consisting only RCC frames fixed joints are used and Model II hybrid is a RCC frames fixed joints are used and for RCC beam-masonry joint hinged joints are used since the shear force hinged joints transfer both gravity and lateral load from $\mathrm{RC}$ beam to wall and finally to ground.

\subsection{Load calculation and analysis}

The building loads such as dead load, live load, seismic load, load combination and mass source were applied as IS code 875:1987 and IS code 1893:2002 for zone V for a typical residential building.

i. Live load: Live load from $1^{\text {st }}$ floor to $3^{\text {rd }}$ floor $=2 \mathrm{KN} / \mathrm{m}^{2}$ Staircase live load $=3 \mathrm{KN} /$ $\mathrm{m}^{2}$

ii. Dead load: Dead load of structure is taken as defined in IS: 875 -1987 in which load is calculated as per unit weight of material used i.e.

Unit weight of R.C.C. $=25 \mathrm{KN} / \mathrm{m}^{3}$

Unit weight of brick masonry $=19 \mathrm{KN} / \mathrm{m}^{3}$

Floor Finnish $=1.5 \mathrm{KN} / \mathrm{m}^{2}$

iii. Seismic Load: For seismic load calculation IS: 1893:2002 is used. Since the building is in lalitpur which lies in earthquake zone $\mathrm{V}$ for which zone factor $(Z)=0.36$, response reduction factor $(R)=5$, importance factor for residential building $(I)=1$, soil type i.e. medium soil $=$ II, damping $=5 \%$. The base shear for building is calculated as:

$V_{B}=A_{h \times W} V_{B}=A_{h \times W}$, where $A_{h=\frac{z I S_{a}}{2 R g}} \quad A_{h=\frac{z I S_{a}}{2 R g}}$

$\mathrm{W}=$ Seismic weight of the building

For Model I the seismic time period is given by

$T_{a}=0.075 h^{0.75}$ and for Model II

direction.

$$
T=\frac{0.09 h}{d^{\frac{1}{2}}} T=\frac{0.09 h}{d^{\frac{1}{2}}} \text { Where } \mathrm{h}=\text { height of building and } \mathrm{d}=\text { base dimension in } \mathrm{x} \& \mathrm{y}
$$

The load combination and mass source is taken as per IS code and also rigid diaphragm provided for each floor.

\section{Results and Discussions}

The seismic resistance decrease when there is increase in lateral load. So, for seismic analysis of building lateral forces such as earthquake load and wind load is very important. The studied build lies in high seismic zone but the effect due to wind load is negligible. The comparison on displacement, drift and time period is carried out to determine the building behavior in various 
seismic conditions.

\subsection{Comparison of Building Displacement}

The maximum story displacements for model I and model II are observed with similar material load condition and material properties. The study show there is higher displacement of each story is much higher in model I with compare to model II in both $\mathrm{x}$ and y directions. The displacement increase distinctively in each direction of model I and there is also increase in displacement as elevation increase in model II but the rate of increase doesn't show rapid variation. The results shows model I shows more movement with respect to ground and model II shows less movement. So, during seismic impact there is more movement of building above ground surface in model I than that of model II.

Table 1: Maximum displacement of models in lateral load conditions

\begin{tabular}{l|llllll}
\hline \multicolumn{2}{l|}{$\begin{array}{l}\text { Max Displacement } \\
\text { Story Response Values }\end{array}$} & & $\underline{\text { X-Dir }}$ & \multicolumn{3}{ll}{} \\
Story & Elevation (m) & $\underline{\text { Model I }}$ & $\underline{\text { Model II }}$ & $\underline{\text { Model I }}$ & $\underline{\text { Model II }}$ \\
Story3 & 10.9728 & 35.243 & 2.912 & 16.169 & 4.324 \\
Story4 & 8.2296 & 29.137 & 2.748 & 12.964 & 3.533 \\
Story2 & 5.4864 & 19.348 & 1.757 & 8.875 & 2.386 \\
Story1 & 2.7432 & 7.645 & 0.802 & 3.693 & 1.127 \\
\hline
\end{tabular}

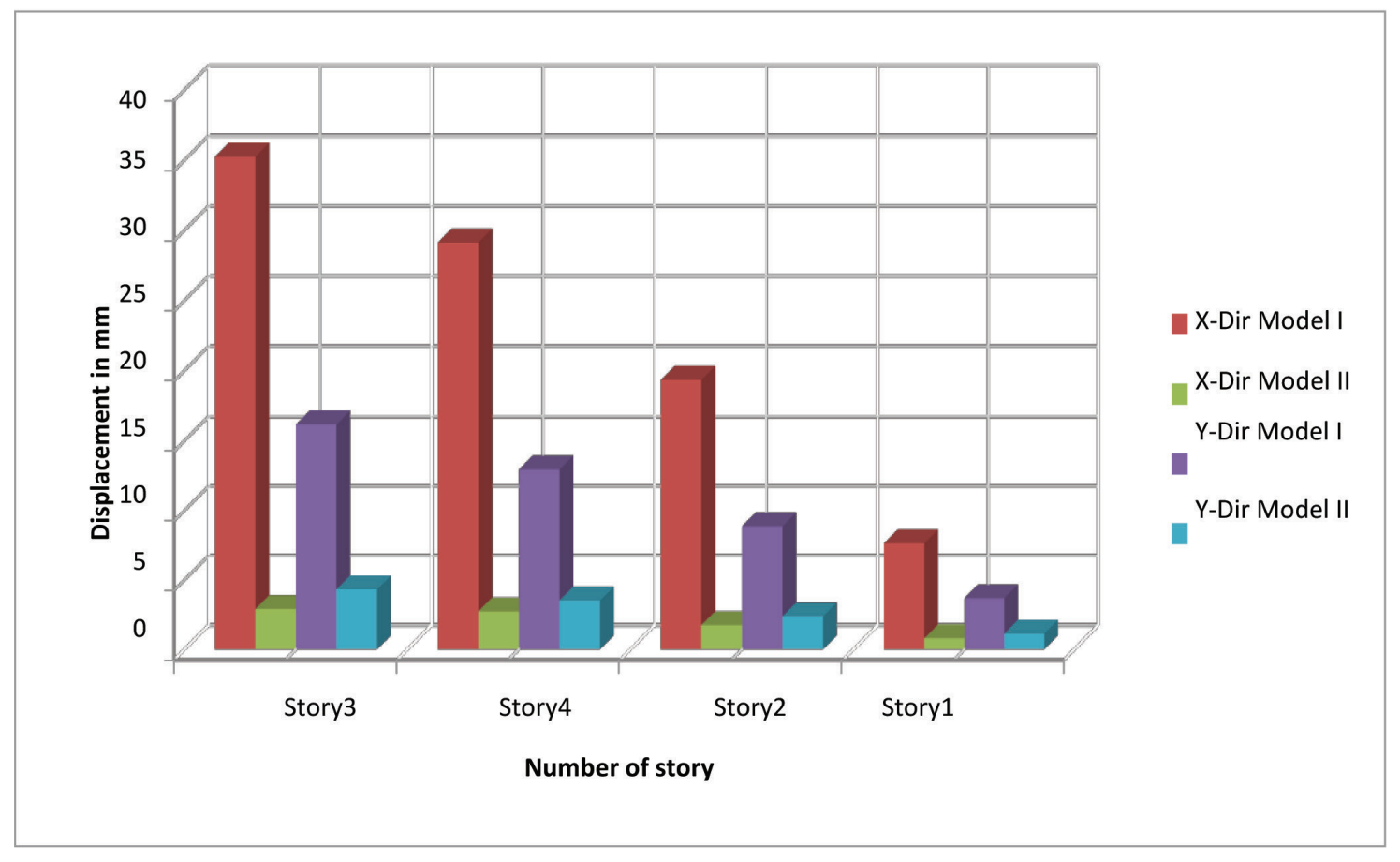

Fig. 3: Story Displacement in Lateral Load Condition 


\subsection{Comparison of Building Drift}

Similarly, while comparing maximum drift of two models, it shows maximum story drift of model I exceed to that of model II and also there is increase in drift value as per increase in floor elevation. The maximum story drift in model I and model II shows the permanent shifting of building structure due to lateral loading is higher in model I than that of model II.

Table 2: Maximum story drift of models in lateral load conditions

\begin{tabular}{|c|c|c|c|c|c|}
\hline \multicolumn{6}{|l|}{ Max Drift } \\
\hline Story Response Values & & $\underline{\text { X-Dir }}$ & & $\underline{\text { Y-Dir }}$ & \\
\hline$\underline{\text { Story }}$ & $\underline{\text { Elevation }(\mathrm{m})}$ & $\underline{\text { Model I }}$ & $\underline{\text { Model II }}$ & $\underline{\text { Model I }}$ & $\underline{\text { Model II }}$ \\
\hline Story4 & 10.9728 & 9.789 & 0.745 & 4.089 & 0.791 \\
\hline Story3 & 8.2296 & 6.106 & 0.99 & 3.205 & 1.147 \\
\hline Story2 & 5.4864 & 11.704 & 0.955 & 5.182 & 1.258 \\
\hline Story1 & 2.7432 & 7.645 & 0.802 & 3.693 & 1.127 \\
\hline
\end{tabular}

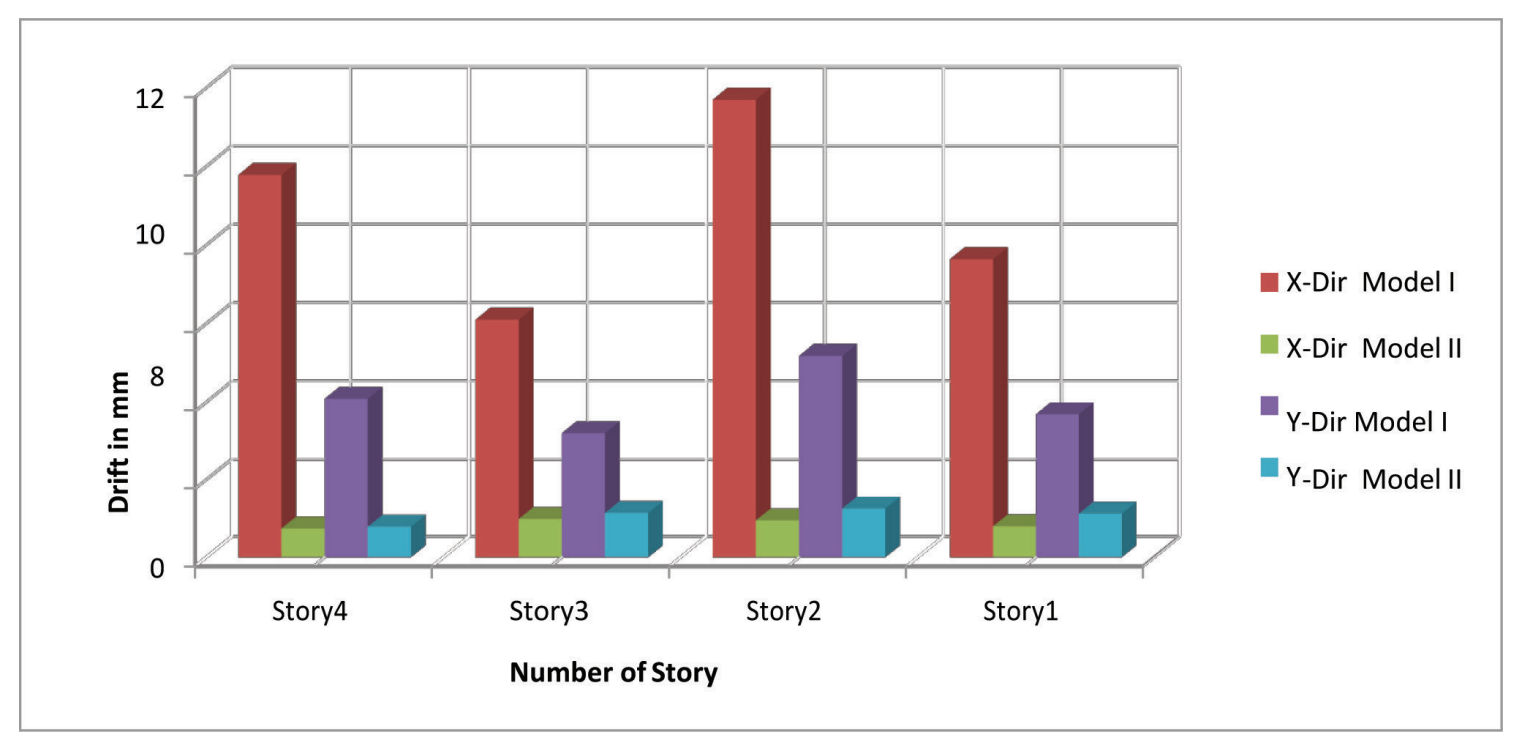

Fig. 4: Story Drift in Lateral Load Condition

\subsection{Comparison of Time Period}

The natural time period of building is a function related to building architect and base dimension of building. It determines the magnitude of building oscillation during seismic conditions. In this study the natural time period of model II is higher than model I. The building with less time is stiffer than building with more time period which shows model II is stiffer than model I. 
Table 3: Modal time period of models in different mode cases

\begin{tabular}{|c|c|c|}
\hline \multirow{2}{*}{ Mode Case } & \multicolumn{2}{|c|}{ Period (sec) } \\
\cline { 2 - 3 } & Modal I & Modal II \\
\hline Modal 1 & 0.868 & 0.375 \\
Modal 2 & 0.648 & 0.26 \\
Modal 3 & 0.282 & 0.155 \\
Modal 4 & 0.228 & 0.1 \\
Modal 5 & 0.212 & 0.058 \\
Modal 6 & 0.164 & 0.054 \\
Modal 7 & 0.14 & 0.036 \\
Modal 8 & 0.136 & 0.026 \\
Modal 9 & 0.119 & 0.021 \\
Modal 10 & 0.105 & 0.018 \\
Modal 11 & 0.052 & 0.012 \\
Modal 12 & 0.037 & 0.009 \\
\hline
\end{tabular}

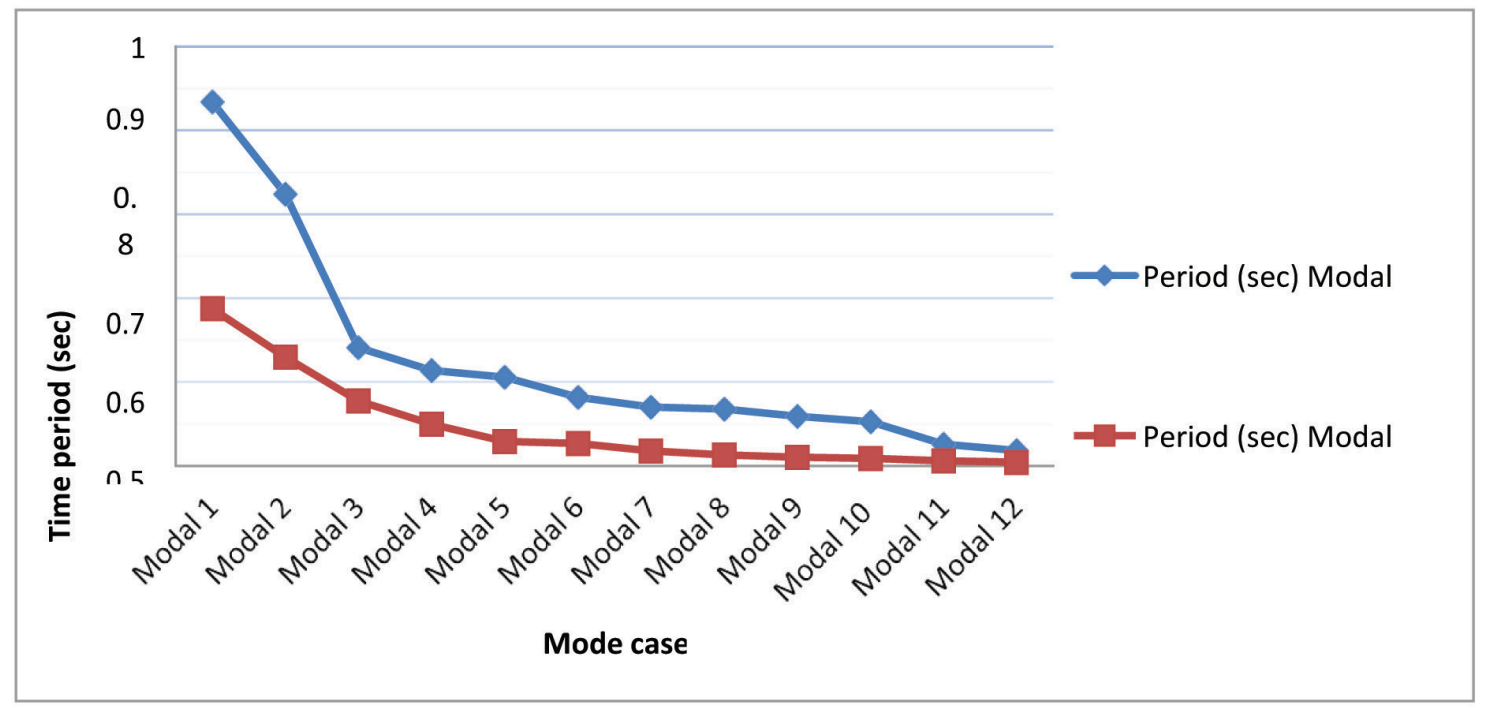

Fig. 5: Graph time period of models against various mode cases

\section{Conclusion and Recommendations}

From the study of one bay structure with special construction conditions, we can conclude that in this particular condition structure with combined RCC frame and masonry structure is more reliable, resistive and economical than construction of RCC building only. The building with load bearing wall has effective lateral load resisting features and do not show more deformation during loading conditions and also provides more stiffness than RCC. The time period obtained from study 
lies in its natural frequency which results in less oscillation during seismic forces. Hence, the more stiff building is less flexible in nature which reduces base shear of building and with less base shear more economic building sections can be designed with reduced frame size and less reinforcement area. As height of building increases the time period of building increase which leads in more flexible structure, so the study is limited to lesser floor height and also advantage of construction of masonry structure combined with RCC frame structure can only be obtained for normal residential building. The study was conducted for unhindered construction with structural building in either and unsafe excavation site. It is only applicable for only special condition as described in Fig. 2. Any further implication of hybrid structure required more study and other building strengthening technologies since the masonry load bearing structure for high rise building also increases seismic weight of building which leads in instability causing failure in ductility and flexibility.

Acknowledgement: I would like to thank my organization Lumanti Support Group for Shelter for providing to work in core area of Lalitpur and also to all members my team in Siddhipur who inspired to work in difficult conditions.

\section{References}

[1] Bhargavi S, Pradeep KR (2015), Comparison between the effect of lintel and lintel band on the global performance of load bearing walls and masonry infilled RC frames. National Journal of Civil Engineering and Technology (IJCIET). 6(2): 68-78.

[2] Cattari S and Lagomarsino S (2013), Seismic assessment of mixed masonry-reinforced concrete buildings by non-linear static analyses. Earthquakes and Structures. 4(3): 241-264.

[3] Cattari S and Lagomarsino S (2014), Performance-based approach for the seismic assessment of masonry historical buildings. Second European conference on earthquake engineering ad seismology . 1(1): 1-12.

[4] Johnson R and Robertson I (2011), Hybrid masonry connector development. University of Hawaii college of Engineering: Department of Civil and Environmental Engineering.

[5] Jurukovski D, Alessi R, Jashkov L, Zarri F, Petkovski M and Diotallevi P (1992), Shaking table test of five reduced scale model of a four-storey brick masonry building, Skopje, Republic of Macedonia: Institute of Earthquake Engineering and Engineering Seismology (IZIIS).

[6] Mal H and Parekh U (2016), Comparative study of conventional structure with monolithic structure. International Journal of Science and Research (IJSR). 5(5): 866-868.

[7] Milosevic J, Bento R and Cattari S (2014), Seismic assessment of a "PLACA" building in Lisbon. Second European conference on earthquake engineering and seismology. 1(1): 1-12.

[8] Mohammed NR, Kumar DA and Md. Sharif UK (2014), A brief study of hybrid masonry structural frame. International Journal of Computer Applications. 99(8): 38-41.

[9] Muhammad A, Gupta CB and Mahmoud I (2015), Comparative analysis of seismic behavior of multi-storey composite steel and conventional reinforced concrete framed structures. International Journal of Scientific \& Engineering Research. 6(10): 1213-1220.

[10] Surekha A, Chaitanya KJD, Arunakanthi E (2014), Analysis and connection designs of precast load bearing wall. IJRET: International Journal of Research in Engineering and Technology. 3(9): $449-457$. 